\title{
Breast Enlargement and Reduction: Results from a Breast Cancer Case-Control Study
}

\author{
Louise A. Brinton, Ph.D., Kathleen E. Malone, Ph.D., Ralph J. Coates, Ph.D., \\ Janet B. Schoenberg, M.P.H., Christine A. Swanson, Ph.D., Janet R. Daling, Ph.D., \\ and Janet L. Stanford, Ph.D. \\ Bethesda, Md., Seatle, Wash., Atlanta, Ga., and Trenton, N.J
}

In a population-based case-control study of breast cancer that included 2174 cases and 2009 population controls under 55 vears of age, prior breast implants were reported by 36 cases versus 44 controls. After adjustment for the matching factors as well as variables associated with both breast cancer risk and breast enlargement (race, family history of breast cancer, body size, screening history), the relative risk of breast cancer associated with a prior implant was $0.6(95 \%$ CI $0.4-1.0)$. The reduced risk persisted with increasing interval since surgery, arguing against selection bias as an explanation. Further, although a deficit of in situ tumors was seen among women with implants $(\mathrm{RR}=0.2)$, the risk associated with implants remained reduced for both localized and distant tumors $(\mathrm{RR}=0.8$ for both stages). In a smaller group of women who had prior breast reduction surgery ( 10 cases, 13 controls), a reduced risk of breast cancer also was observed $(\mathrm{RR}=0.7$, 95\% CI 0.3-1.6). The results of this study must be interpreted cautiously because of the small number of women involved and reliance on patient reports of prior operations. In not showing any elevation in breast cancer risk following a breast implant, our results confirm several record linkage studies but contradict some clinical studies that suggest an adverse effect. Additional investigations are needed in relation to specific types of breast implants, including the polyurethane-coated implants, which have been linked to high cancer rates in laboratory animals. (Plast. Reconstr. Surg. 97: 269, 1996.)

Although it is estimated that approximately 1 to 2 million women in the United States have received either silicone gel- or saline-filled breast implants, ${ }^{1}$ there has been limited investigation of their long-term health effects. Of particular concern has been their potential effect on subsequent breast cancer risk, given a number of clinical reports of a positive association, ${ }^{2-9}$ as well as the recognition of an impaired ability to detect breast lesions with mam- mography in women with breast implants. ${ }^{10-14}$ In line with these observations, one study showed later stages at diagnosis of breast cancer among women with augmented breasts. ${ }^{15}$

Three follow-up studies have observed no evidence of increased breast cancer in women receiving implants for cosmetic reasons. ${ }^{16-18}$ However, these studies all involved only record linkage, with limited abilities to control for correlated lifestyle factors that could independently affect breast cancer risk. Although all these studies showed relative risks of breast cancer less than unity, it has been suggested that lack of control for certain factors (e.g., breast size, body weight) could have resulted in imprecise estimates of risk. ${ }^{16,17,19}$ In addition, one of the studies has been criticized for incomplete follow-up, leading to speculation that this would have underestimated the true risk. ${ }^{20}$

In a recently completed case-control study of breast cancer in younger women, we had the ability to assess the relationship of risk to prior breast implants while also considering effects of a number of other predictors of breast cancer risk. In addition, this study also provided some opportunity to examine risk in relation to the rarer occurrence of breast reduction surgery, which has been linked in at least one epidemiologic study to reduced breast cancer risk. ${ }^{21}$

\section{Patients And Methods}

This population-based case-control study included women newly diagnosed with breast cancer in the two metropolitan areas of Atlanta, Georgia, and Seattle/Puget Sound, Washing-

From the Environmental Epidemiology Branch of the National Cancer Institute, the Fred Hutchinson Cancer Research Center, the Department of Epidemiology. Rollins School of Public Health, at Emors Lniversits, and the Special Epidemiology Program at the New Jerses State Department of Health. Received for publication February 28, 1995; revised May 12, 1995. 
ton, and in five counties of central New Jersey. In Seattle and New Jersey, cases were restricted to women less than 45 years of age, while in Georgia the age range was extended through age 54. All women of these ages newly diagnosed with in situ or invasive breast cancer during the period May 1, 1990 through December 31, 1992 were identified through rapid ascertainment systems, with periodic checks made against existing cancer registries to determine the completeness of case ascertainment. Hospital records of these patients were abstracted to document details on the clinical and pathologic characteristics of the breast tumors.

Controls in all areas were frequency matched by geographic area and age to the expected distribution of cases and were identified through random digit dialing. ${ }^{22}$ A 90.5 percent response rate to the telephone screener was obtained from the 16,254 telephone numbers assessed as residential.

Personal interviews, which lasted an average of 71 minutes, collected detailed information regarding demographic factors; reproductive, breast-feeding, and menstrual histories; contraceptive behavior; use of exogenous hormones; medical and screening history; anthropometry and physical activity; adolescent diet; alcohol consumption; smoking; occupations; family history of cancer; and certain lifestyle factors and opinions about cancer causation. With respect to a history of breast surgery, subjects were asked to provide details on all types of procedures, including aspirations, biopsies, lumpectomies, and enlargement or reduction operations. For each procedure reported, details were obtained on the date of surgery, which breast was involved, and where the operation was performed.

Completed interviews were obtained from 2203 of the 2551 eligible cases ( 86.4 percent) and 2009 of the 2571 eligible controls (78.1 percent). Reasons for nonresponse included refusals (5.4 percent physician refusal and 6.4 percent subject refusal in cases versus 18.5 percent in controls), death $(0.4$ versus 0.2 percent), illness ( 0.6 versus 0.2 percent), a move outside the study area ( 0.6 versus 2.3 percent), and other miscellaneous reasons ( 0.2 versus 0.8 percent). Because controls were identified through telephone sampling, the 29 cases without residential telephones at diagnosis were eliminated, leaving 2174 cases available for analysis. Among the controls, an overall response rate of 70.7 percent was achiev- ed through multiplication of the telephone screener and interview response rates.

All risk factor information, including that pertaining to prior breast operations, was truncated at the date of diagnosis for cases or the date of completion of the random digit dialing screener for controls (known as the reference date). The relationship of prior breast surgery to risk of breast cancer was assessed through calculation of odds ratios as approximators of relative risks (RRs). A relative risk of 1.0 would indicate no association between implants and breast cancer risk. Further, implants would be associated with a doubling of risk for a relative risk of 2.0 and a halving of risk for a relative risk of 0.5. Logistic regression analyses were employed to control for effects of extraneous variables and to derive maximum likelihood estimates of relative risks and their 95 percent confidence intervals (CI). ${ }^{23}$ A lower limit (or upper limit in the case of reduced risk) of a confidence interval exceeding 1.0 would indicate that the associated relative risk was statistically significant at a $p$ value of less than 0.05 .

\section{RESUITS}

A total of 36 ( 1.7 percent $)$ of the cases versus 44 (2.2 percent) of the controls reported having had surgery to enlarge their breasts, resulting in a relative risk (adjusted only for the matching factors of study site and age) of $0.7(95 \%$ C. $0.5-1.2)$. Fewer women reported surgery to reduce their breasts, namely, 10 (0.5 percent) of the cases and 13 ( 0.6 percent) of the controls $(\mathrm{RR}=0.7,95 \%$ CI $0.3-1.6)$.

Risk factors for breast cancer in the study (adjusted for each other) included being nonwhite ( $R R=1.2$ compared with Caucasians), a late age at first birth $(R R=1.6$ for $30+$ versus $<20$ years), a history of a biopsy for benign breast disease $(\mathrm{RR}=1.4)$, a history of breast cancer in a mother or sister $(\mathrm{RR}=2.3)$, and long-term use of oral contraceptives $(\mathrm{RR}=1.3$ for $10+$ years of use versus use $<6$ months). Heavier women were at a decreased risk $(R R=$ 0.8 for body mass indices of $27+$ versus $<23$ ). Other suggested risk factors, including education, age at menarche, number of incomplete pregnancies, bra cup size, cigarette smoking, and regular consumption of alcoholic beverages, were not strongly related to risk. Women who had ever practiced breast self-examination 1 or more years prior to interview had a relative risk of 0.8 , while those who had had a mam- 
mogram during this period had a relative risk of 1.1 .

Among the controls, there was substantial variation in the proportion of women with breast implants according to several factors (Table I). Notably, the percentages were highest in subjects from Atlanta, white women, subjects with vocational schooling or some college, those with early ages at a first birth, thin women, those with a mother or sister with breast cancer, long-term users of oral contraceptives, and those who had a mammogram at least 1 vear prior to study enrollment. These proportions were not changed substantially by age adjustment, since the mean ages were not significantly different between the controls with (43.9 veats) and without implants (40.9 years). The prevalence of breast reduction surgery in the controls did not vary as substantially according to these same factors, although this analysis was limited by small numbers.

To control for possible confounding effects of these risk factors, the relative risks associated with both breast enlargement and reduction surgery were adjusted for the matching factors as well as for race, body size, family history of breast cancer, and history of mammography (Table II). The reduced risk associated with breast enlargement persisted $(\mathrm{RR}=0.6,95 \% \mathrm{CI}$ 0.4-1.0); further, the decrease in risk was most marked for women who had their surgery at age 35 or older $(\mathrm{RR}=0.5,95 \%$ C.I $0.3-1.0)$, as well as those with 10 or more vears since implantation $(\mathrm{RR}=0.5,95 \%$ (.I $0.2-0.9)$. The risks were decreased in the combined categories of ages $(<35,35+)$ and years since implantation $(<10$, $10+)$, except for those who obtained their inplants prior to age 35 and who had less than 10 vears of follow-up $(\mathrm{RR}=1.5,95 \%$ (.I $0.6-4 .(0)$.

Ages at diagnosis were similar between breast cancer cases with and without implants (respective means of 41.1 and 41.4 years). The relative risk associated with having an implant decreased with increasing age at breast cancer diagnosis, being $0.9(95 \%$ CI $0.4-2.0)$ for the 13 women diagnosed prior to age 40, $0.7(0.3-1.5)$ for the 14 women with breast cancers at ages 40 to 44 , and $0.4(0.2-0.9)$ for the 9 women with breast cancers diagnosed at ages 45 or older (all of whom were from the Atlanta area).

Breast enlargement associations within categoriesof selected risk factors are shown in Table III. Reduced risks associated with implants were seen in all categories of body size (as assessed by body mass index). However, when the effects of breast implants were examined by bra size, the reduced lisk was restricted to women with cup sizes of B or greater. The reduced risk associated with implants was particularly apparent among women with a mother or sister with breast cancer, although only 4 cases and 7 controls were involved $(\mathrm{RR}=0.2,95 \%$ CI $0.0-0.7)$. The only risk factor category where implants were not associated with a reduced risk was women who had never had a mammogram (6 cases, 5 controls; $R R=1.4$ ). Consistent with this, the risk associated with implants was higher $(\mathrm{RR}=0.9)$ among subjects who had not had a mammogram recently (i.e., within 1 to 6 years prior to reference date) than among subjects who reported two or more mammograms during this period $(\mathrm{RR}=0.7)$.

A total of 5.6 pereent of the women with breast implants were diagnosed with in situ tumors, 58.3 pereent with localized tumors, and 36.1 pereent with distant 1 umors. When rates of breast implants were examined within each stage group and compared with rates among the entire control group, the reduced risk associated with breast implants was most marked for in situ tumors $(\mathrm{RR}=0.2,95 \%$ CI $0.0-0.8)$. However, the risk related to breast implants remained reduced for localized $(\mathrm{RR}=0.8,95 \%$ CI $0.5-1.4)$ as well as more advanced stage invasive tumors $(\mathrm{RR}=0.8,95 \%$ CI $0.4-1.5)$.

After adjustment for other breast cancer predictors, women with prior breast reduction surgery had a relative risk of 0.7 (95\% (a $0.3-1.6)$ (see Table II). No distinctive relationships were noted according to either age at surgery or interval since surgery, although numbers for this analysis were limited.

\section{Discosiston}

In this study we found that women who had received breast implants were not at an excess risk of developing breast cancer. This finding agrees with all the other analvtical studies that have examined the relationship. ${ }^{16-18.21 .25}$ In addition, although limited by their design, the results of three surveys among plastic surgeons that inquired about the occurrence of cancer also found no clevations in breast cancer risk. ${ }^{26-24}$ Of interest is that all the previous analytical studies, except one, ${ }^{24}$ have found breast cancer risks to be reduced, although in only one study was the effect statistically significant. ${ }^{16} \mathrm{De}$ spite the consistency of the results from these epidemiologic studies, the relationship of breast implants to breast cancer risk remains 
TABLE I

Pereent of Controls with Breast Enlargement and Breast Reduction Surgery by Selected Factors

\begin{tabular}{|c|c|c|c|}
\hline & No, of Comtrols & $\begin{array}{l}\text { Percent Breats } \\
\text { Fulargentent }\end{array}$ & $\begin{array}{l}\text { Percent Breats } \\
\text { Reduction }\end{array}$ \\
\hline Total & 2009 & 2.2 & 0.6 \\
\hline \multicolumn{4}{|l|}{ Sudy site } \\
\hline Atlanta & 430 & 3.3 & 1.2 \\
\hline New Jersey & 465 & 1.1 & 0.2 \\
\hline Scattle/Puget Sound & (6) & 1.3 & 0.8 \\
\hline \multicolumn{4}{|l|}{ Age } \\
\hline$<35$ & 291 & 1.4 & 0.3 \\
\hline $35-.39$ & 474 & 1.9 & 0.8 \\
\hline $40-44$ & 740 & 1.9 & 0.8 \\
\hline $45-49$ & 264 & 2.6 & 0.4 \\
\hline $50-54$ & 240 & 4.2 & 0.4 \\
\hline \multicolumn{4}{|l|}{ Race } \\
\hline White & 1571 & 2.7 & 0.8 \\
\hline Nrican-Ancrican & 326 & 0.0 & 0.3 \\
\hline ()her & 112 & 0.9 & 0.0 \\
\hline \multicolumn{4}{|l|}{ Education } \\
\hline lligh school or less & 593 & 1.8 & 1.0 \\
\hline Vocational school & 165 & 3.0 & 0.0 \\
\hline Some college & 519 & 3.5 & 0.8 \\
\hline college graduate & 467 & 1.7 & 0.2 \\
\hline Post graduate & 271 & 0.7 & 0.7 \\
\hline \multicolumn{4}{|l|}{ Age al first birth } \\
\hline 20 & 378 & 2.9 & 0.8 \\
\hline $20-24$ & 584 & 2.7 & 0.5 \\
\hline $25-29$ & +11 & 1.5 & 0.5 \\
\hline $30+$ & 24.3 & 1.2 & 0.8 \\
\hline Nulliparous & 392 & 2.0 & 0.8 \\
\hline \multicolumn{4}{|l|}{ Previous breast biopser } \\
\hline$N_{0}$ & 1965 & 2.2 & 0.7 \\
\hline Yes & 44 & 1.6 & 0.0 \\
\hline \multicolumn{4}{|l|}{ Beods mass index: } \\
\hline$<23$ & 607 & 4.1 & 0.5 \\
\hline $23-26$ & 610 & 2.1 & 0.5 \\
\hline $27+$ & 680 & 0.4 & 1.0 \\
\hline \multicolumn{4}{|l|}{ Uamal adlull bra size. } \\
\hline 1 & 318 & 4.4 & 0.0 \\
\hline B & 941 & 2.6 & 0.0 \\
\hline (: & 494 & 1.2 & 0.4 \\
\hline 1) & 230 & 0.0 & 4.8 \\
\hline \multicolumn{4}{|c|}{ Breast cancer in a mother or sister } \\
\hline No & 1877 & 2.10 & 0.7 \\
\hline Yes & 1.32 & 5.3 & 0.0 \\
\hline \multicolumn{4}{|c|}{ Yeats of ure of oral contraceptives } \\
\hline $0-<6$ months & 609 & 1.8 & 0.7 \\
\hline$<5$ vears & 731 & 1.8 & 0.4 \\
\hline $5-9$ ycars & 413 & 3.4 & 0.7 \\
\hline $10+$ & 253 & 2.4 & 1.2 \\
\hline \multicolumn{4}{|c|}{$\begin{array}{l}\text { Fer had a mannogram I year } \\
\text { prior to referenec date }\end{array}$} \\
\hline No & 869 & 0.6 & 0.9 \\
\hline Yes & 1139 & 3.4 & 1.0 \\
\hline \multicolumn{4}{|c|}{$\begin{array}{l}\text { Number of mammograme } 1 \text { to } 6 \\
\text { years prior to reference date }\end{array}$} \\
\hline 0 & $942 \%$ & 1.0 & 0.2 \\
\hline 1 & 472 & 3.8 & 1.1 \\
\hline 2 & 250 & 2.4 & 1.2 \\
\hline $3+$ & 342 & 3.2 & 0.9 \\
\hline
\end{tabular}

Sitc-specilic tatee limited to subjects th vears of age.

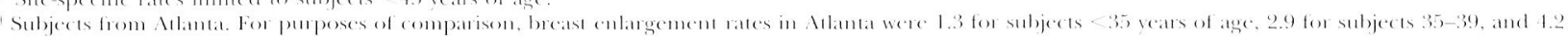
fin subjects $10-44$

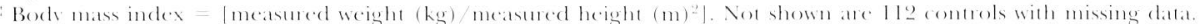

Referenee date defined an the time when subjects were ielentified as eligible for study throngh the telephone sereener.

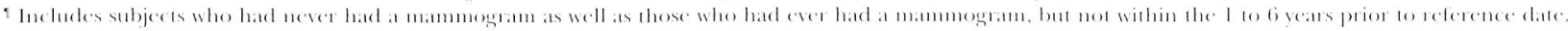


T. IBI.F. II

Relative Risks of Breast Cancer Associated with Breast Lnlatgement or Breast Reduction Surgery

\begin{tabular}{|c|c|c|c|c|c|c|}
\hline & \multicolumn{3}{|c|}{ Breast bulangement } & \multicolumn{3}{|c|}{ Butat Reduction } \\
\hline & Catere & RR & $95 \div$ ( 1 & Cunes & $R R$ & $95 \div(1$ \\
\hline \multicolumn{7}{|c|}{ Fer had sugery } \\
\hline$x_{0}$ & 21.38 & $1.00)$ & & 2164 & 1.00 & \\
\hline Yes & 36 & 0.64 & $0.1-1.0$ & 10) & (1).71 & $0.3-1.4$ \\
\hline \multicolumn{7}{|c|}{ Age at surgers } \\
\hline$<30$ & 10) & 0.80 & $0.3-2.0$ & 4 & (1).64 & $0.2-2.4$ \\
\hline $30-34$ & 11 & 0.76 & $0.3-1.8$ & 2 & 1.06 & $0.1-7.7$ \\
\hline $35+$ & 15 & 0.51 & $0.3-1.0$ & 4 & 0.67 & $0.2-2.4$ \\
\hline \multicolumn{7}{|c|}{ Years since surgers } \\
\hline$<5$ & 12 & 0.78 & $0.3-1.8$ & () & 0.00 & \\
\hline $5-9$ & 12 & 0.86 & (0. $4-2.0$ & 6 & 1.41 & $0.1-5.1$ \\
\hline $10+$ & 12. & 0.46 & $0.2-0.9$ & 4 & 0.69 & $0.2-2.4$ \\
\hline
\end{tabular}

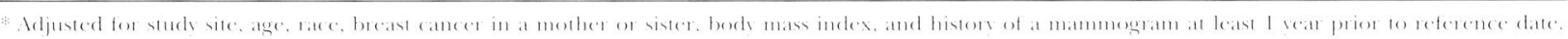

TABI.E III

Relative Risks of Breast Cancer Associated with Breast Enlargement by Other Risk Factors

\begin{tabular}{|c|c|c|c|c|}
\hline & Catere with lomplants & Controls with Implants & RR & $95 \div(1$ \\
\hline \multicolumn{5}{|c|}{ Bode mass index } \\
\hline$<23$ & 24 & 25 & 0.71 & $0.1-1.3$ \\
\hline $29-26$ & 11 & 13 & 0.69 & $0.3-1.6$ \\
\hline $27+$ & 1 & 3 & 0.36 & $0 .(1-3.4$ \\
\hline \multicolumn{5}{|c|}{ Usual adtult bra size } \\
\hline A & 14 & 14 & 0.94 & $0.4-2.1$ \\
\hline $\mathrm{B}$ & 17 & 24 & 0.54 & $0.3-1.0$ \\
\hline$(i+$ & 5 & 6 & 0.62 & $0.2-2.1$ \\
\hline \multicolumn{5}{|c|}{ Breast cancer in a mother or sister } \\
\hline No & 32 & 37 & 0.77 & $0.5-1 . .3$ \\
\hline Yes & 4 & 7 & 0.18 & $0.0-0.7$ \\
\hline \multicolumn{5}{|c|}{$\begin{array}{l}\text { Ever had a mammogram } 1 \text { year prior } \\
\text { to reference date }\end{array}$} \\
\hline$N_{0}$ & (i) & 5 & 1.43 & (0. $4-4.8$ \\
\hline Yes & 30 & 39 & 0.5 .5 & $0.4-0.9$ \\
\hline \multicolumn{5}{|c|}{$\begin{array}{l}\text { Number of mammograme } 1 \text { to } 6 \\
\text { rears prior lo reference date }\end{array}$} \\
\hline () & 7 & !) & 0.86 & (1).3-2.4 \\
\hline 1 & 11 & 18 & 0.55 & $0.2-1.2$ \\
\hline $2+$ & is & 17 & 0.67 & (1).3-1.3. \\
\hline
\end{tabular}

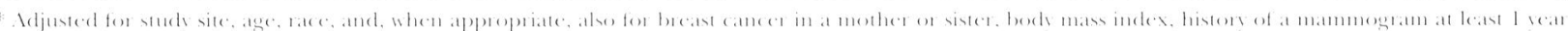

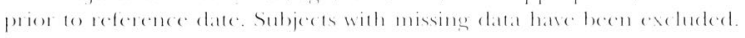

monesolved because of either small sample sizes, incomplete follow-up, or inability to control for other predictors of breast cancer risk.

Although our study relied on patient reports of surgery and was further limited by absence of information on type of implants (e.g., silicone gel versus saline), a strength was in its ability to control for factors associated with the seeking of implants, which may have independently affected subsequent breast cancer risk. Of particular concern in past studies has been whether women at low risk of breast cancer may preferentially seek implants. Notably, concern has been expressed as to whether an overrepresentation of thin women or women with small breasts may have led to the reduced risks observed in previous studies.
In out study, thin women preferentially received implants, but thinness was associated with an elevation in risk, a relationship also observed in other studies of younger women. Thus adjustment for body size served only to strengthen the reduced risk associated with a prior implant. Further, reduced risks associated with a prior implant were observed across all categories of body size. Thus it seems unlikely that body size could explain the reduced risks associated with implants in this study.

The effect of breast size on explaining breast implant associations is more complex. Although the seeking of breast implants was strongly related to breast size (as estimated by bra cup size), breast size is generally not recognized as a breast cancer risk factor. 1 .32 How- 
ever, it is widely recognized that bra size is only a crude indicator of breast or mammary gland size, with mammary gland size being hypothesized to be the better predictor of breast cancer risk." Consistent with this is our previous observation of an elevated risk associated with large bra size among thin women, possibly due to bra size being a better measure of mammary gland size in these women. ${ }^{34}$ Thus our finding of only a minimally reduced risk associated with a prior implant among women with A cup sizes $(\mathrm{RR}=0.9)$ might reflect that women seeking implants have small mammary glands (and thus fewer susceptible cells at risk). Unfortunately, limited numbers did not allow us to further explore this potential interaction. In addition, we were unable to give further attention to the significant reduction in risk among women with a family history who received implants.

The effect of more intensive screening as an explanation for reduced risks of breast cancer among women with implants is an issue that bears particular attention. We attempted to evaluate this issuc by examining timing of operation relationships (age at and interval since), stage effects, and associations by screening history. If women obtained more sereening prior to their implants, or if they received screening as part of their plastic surgical workup, then reduced risks should be apparent during the first few years following implantation, since potentially eligible cases would have been identified prior to inclusion in our studv. However, we observed the largest reduction in risk associated with an implant for subjects with extended intervals since surgery. Further, given difficulties in mammographic visualization, because of either implants ${ }^{14}$ or associated complications (e.g., contracture), the possibility of detection bias was considered. If implantation had interfered with detection, we would expect to see a reduced risk during the first few years after surgery, with an increase at later years, particularly for larger cancers not detected earlier. However, apart from a tendency in our study for women with implants not to be diagnosed with in situ tumors, we saw no such relationships. Our results are consistent with both the Los Angeles ${ }^{17}$ and the Alberta, Canada, ${ }^{35}$ follow-up studies, where women with breast implants were not diagnosed at later stages than women with breast cancer in the general population.

Thus our findings are not entirely consistent with more intensive screening as the explanation for reduced breast cancer risk following a breast implant, although mention must be made of the failure to observe a reduction in risk among the small group of women who had implants and never had a mammogram. The complexities involved in the assessment of screening as an explanation for implant associations necessitates further evaluation of this issue. However, since relationships could not be attributed entirely to screening effects, further attention should focus on other explanations for a reduced risk associated with implants, e.g., compression of the implants on breast tissue, decreased blood supply, or an enhanced immunologic response. ${ }^{36}$

Similar to the one previous study ${ }^{21}$ on the topic, we found a reduced risk of breast cancer following breast reduction surgery. Our relative risk of 0.7 was very similar to the risk of 0.6 found in the other study, which involved follow-up of 1245 Danish women surgically treated for breast hypertrophy. In that study, the greatest reduction in risk was observed 10 or more vears after the operations in women who had $600 \mathrm{gm}$ or more of breast tissue removed, suggesting the importance of the removal of potential foci of cells for cancer development.

In summary, breast implants do not appear to predispose to an increased risk of subsequent breast cancer, as has been hypothesized in some clinical reports. We also failed to note that breast implants cause a substantial delay in diagnosing breast cancers (apart from a slightly lower rate of diagnosis of in situ cancers in these women). The results are thus reassuring, although further studies are needed to address some issues that could not be resolved by our study, including effects of breast implants in older women. Further, studies are needed on risks associated with specific types of implants, including the more recently introduced polyurethane-coated implants, which have been linked to increased rates of mammary cancer in selected laboratory animals. 37.38

\section{Louise A. Brinton, Ph.D. \\ Environmenlal Epidemiology Branch National Cancer Institute \\ Execulioe Plaza North, Room 443 Bethesda, Mo. 20892}

\section{REFERENC:LS}

1. Angell, M. Breast implants-Protectionor patternalism? N. Engl. J. Med. 326: 1695, 1992

2. Benatent, W. I. Treatunent of bilateral breast carcinomas in a patient with silicone-gel breast implants. Plast. Reconstr. Surg. 51: 588, 1973.

3. Bingham, II. G., Copeland, E. M., Hackell, R., el al. 
Breast cancer in a patient with silicone breast inplants after 13 vears. Ann. Plast. Surg. 20: 236, 1988.

4. Bowers, D). (., Jr., and Radlauer, (. B. Breast cancer after prophylactic subculaneous mastectomies and reconstruction with Silastic prostheses. Plast. Reconstr. Surg. 4t: 541, 1969.

5. Gottlicb, V., Muench, A. G., Rich, J. D., etal. Carcinoma in augmented breasts. Ann. Plast. Surg. 12: 67, 1984.

6. Holt, R. W., and Spear, S. L. Cancer in the augmented breast: Diagnosis and treatment. Breast 10: 16, 1984.

7. Hoopes, J. E., Edgerton, M. T., Jr., and Shellev, W. Organic synthetics for augmentation mammaplasts: Their relation to breast cancer. Plast. Reconstr. Surg. 39: 263,1967

8. Lafreniere, R., and ketcham, A. S. Breast carcinoma postaugmentation mammaplasty: Therapy with limited surgers and radiation. J. Surg. Onool. 35: 99, 1987.

9. Silverstein, M. J., Handel, N., Gamagani, P., etal. Breast cancer in women after augmentation mammoplasty. Arch. Surg. 129: 681, 1988

10. Handel, N. Silverstein, M. J., Gamagani, P., etal. Factors affecting mammographic vistalization of the breast after augmentation mammaplasty. J.A.M.A. 268: 1913.1992.

11. Haves. H., J1., Vandergrift, J., and Diner, W. (.) Mannmography and breast implants. Plast. Reconstr. Surg: 82: 1,1988 .

12. Leibman. A. J.. and Kruse, B. Breast cancer: Mammographic and sonographic lindings after augmentation mammoplasty. Retdiology 174: 195, 1990.

13. Monsees, B. S.. and Destouet, J. M. Mammography in aesthetic and reconstructive breast surgery. Perspect. Plast. Surg. 5: 103, 1991.

14. Silverstein, M. J., Handel, N., and Gamagami, P. The effect of silicone-gel-filled implants on mammography. Cancer 68: 1159, 1991.

15. Silverstein, M. J., Gierson, E. D., Gamagami, P., et al. Breast cancer diagnosis and prognosis in women alugmented with silicone gel-filled implants. Cancer 66: 97 . 1990 .

16. Berkel, H., Birdsell, D. C., and Jenkins, H. Breast angmentation: A risk factor for breast cancer? N. Lingl. I. Med. 326: 1649,1992

17. Deapen, D. M., and Brodv, (. S. Augmentation manmaplasty and beast cancer: A to-vear update of the Los Angeles study. Plast. Reconstr. Surg. 89: 6600, 1992.

18. Melaughlin, J. K., Frammeni, J, F.,Jr, Olsen, J., etal. Re: Breast implants, cancer and ststemic sclerosis. J. Nall. Cinner Inst. 86: 142. 1994.

19. Modan, B. Breast augmentation and the risk of subsequent breast cancer (Letter). N. Engl.J. Med. 328:661. 1993.

20. Brvant, H., Brasher, P. M. A., van de Sande, J. H., et al. Review of methods in "Breast augmentation: A risk factor for breast cancer?" N. Engl. J. Med. 330: 293. 1994.
21. Lund, K., Ewerte, M., and Schon, (;. Breast cancer incidence subsequent to surgical reduction of the female breast. Serond. J. Plast. Reconstr. Surg. 21:209. 1987.

22. Waksberg, J. Sampling methods for random digit dialing. J. Am. Stal Assor. 79: 40, 1978

23. Breslow, N. F, and Dav, N. E. Statistical Hethods in Cancen Rersearch. Vol. 1: The Analysis of Case-Control Studies. Loon, France: International Agence for Research on Cancer, 1980.

24. Glasser, J. W. Communication to Carl A. Larson, Director, Surgical and Rehabilitation Devices Division. Food and Drug Administration, January 12, 1989

25. Nalone, K. E., Stanforel, J. I.., Daling, J. R., et al. Implants and breast cancer (I etter). Lancet 339: 1365. 1992.

26. De Cholnoky, T. Augmentation mammaplasty: Survey of complications in 10.941 patients by 265 surgeons. Plese. Reconstr. Sure. 45: 573, 1970.

27. Harris, H. I. Survey of breast implants from the point of view of carcinogenesis. Plest. Reconstr. Surg. 28: 81, 1961 .

28. Snvderman, R. K., and lizarde, J. (;. Statistical studv of malignancies found before, during. of after routine breast plastic operations. Plast. Reconstr. Surg. 25: 253. 1960 .

29. Brinton, L. A., and Swanson, (.. A. Height and weight at various ages and risk of breast cancer. Ann. Lefide miol. 2.: 597, 1992.

30. London, S. J.. Coldit\% (. A. Stampfer, M. J., ctal. Prospective studv of relative weight, height, and risk of breast cancer. J.A.M.1. 262: 2853, 1989.

31. Hirohata, T., Nomura, A. M. Y., and kolonel, L. N. Breast size and cancer. Br. Med. J. 2: 641, 1977.

32. Valaoras, V. G., MacMahon, B., Trichopoulos, D., et al. Lactation and reproductive histories of breast cancer pationts in greater Athens, 1965-67. Inl. J. Cancer 4: $350,1969$.

33. Trichopoulos, D., and Lipman, R. D. Mammary gland mass and breast cancer risk. Fifidemiology 3: 523, 1992.

34. Swanson, C. A. Coater, R. J., Schoenberg, J. B., et al. Bodv size and breast cancer risk anong women under age 15. Am. J. Expidemiol. (in press).

35. Birdsell, D). C...Jenkins, H. and Berkel, H. Breast cancer diagnosis and survisal in women with and without breast implants. Plast. Reromstr. Surg. 92: 795, 1999.

36. Su, (. W., Drevfuss, D. A., Krirek, T. J., (-1 al. Silicone implants and the inhibition of cancer. Plast. Recomser. Surg. 90: 513, 1995

37. Cards. R. H. Cancinogenicits and chonic toxicits of 2, 4-toluenediamine in F34t rats. J. Nall. Camer Inst. (i2: 1107.1979

38. International Agenos for Research on Cancer. IARC Monographs on the Lualuation of the Carrmogenic Risk of Chemeals to Humans - Some Chemicals L'sed in Plastics and Elastomers, Vol. 39. I von, France: International Agency for Research on Cancer. 1986 